\title{
Global pledge not readily achieved
}

$\mathrm{T}$ he pledge was ambitious, and welcome, but skeptics are concerned that the next step developing and implementing policies, programs and more specific targets that actually help reduce the incidence of premature deaths caused by noncommunicable diseases (NCDs) will be far more problematic.

Still, the " 25 by 25 " (a $25 \%$ reduction by 2025) target which World Health Assembly member nations agreed to in late May is a "decisive step forward," says Ann Keeling, president of the International Diabetes Federation and chairperson for the NCD Alliance, a network of over 2000 health organizations. "This is the first time governments have adopted a global target on NCDs."

Nevertheless, a host of issues remain regarding how the target might possibly be achieved, including questions of financing, as well as reconciling the $25 \%$ objective with the reality that many of the key risk factors - such as smoking, obesity and aging - for NCDs are on the uptick in developing countries, in which $80 \%$ of the globe's 36 million NCD-related premature deaths annually occur. To achieve the target through risk reduction measures is probably demographically impossible, forcing the short-term focus onto medical and political interventions.

WHO had been instructed by the United Nations to develop global NCD targets and some manner of global surveillance network (www.un.org/en /ga/ncdmeeting2011/pdf/NCD_draft _political_declaration.pdf). Yet achieving any manner of consensus on stiffened trade or other measures to regulate tobacco, alcohol or unhealthy products, or to provide additional financial resources to help developing countries treat NCDs, has thus far been difficult (www.cmaj.ca/lookup/doi/10.1503/cmaj .109-4011).

Still, some hope that the NCD pledge itself will galvanize action, much in the manner that the Millennium Development Goals adopted by the UN

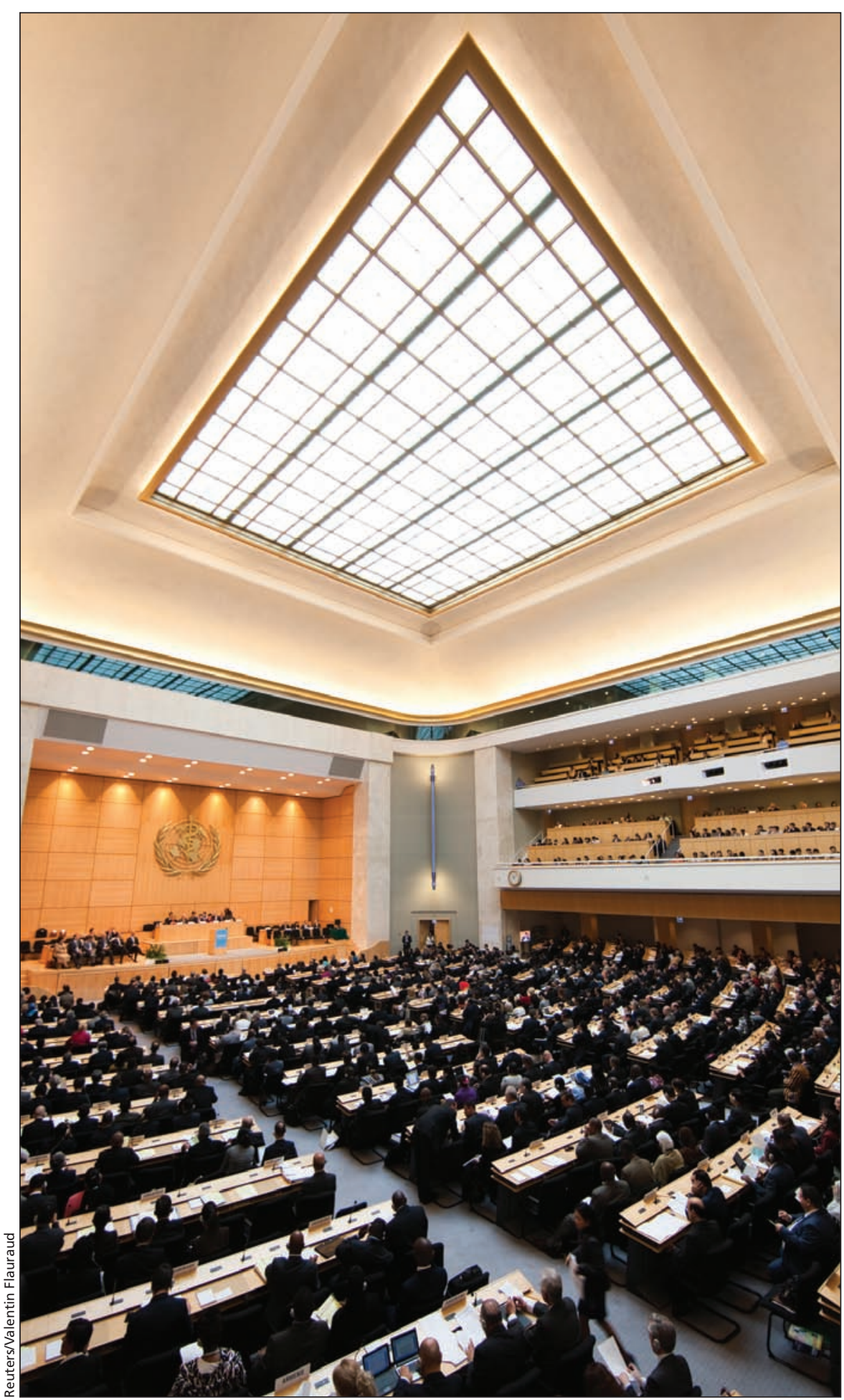

Delegates to the 65th World Health Assembly at the United Nations headquarters in Geneva, Switzerland, adopted a global target of a $25 \%$ reduction in premature mortality from noncommunicable diseases such as cardiovascular disease, cancer, diabetes and chronic respiratory diseases by 2025 . 
in the year 2000 prompted action to lower infectious disease, maternal and childhood mortality rates.

Reducing premature deaths due to NCDs such as cardiovascular diseases, cancer, diabetes and chronic respiratory diseases will require similar responses from governments around the world, Keeling says. "We need decisive action on the remaining targets up for discussion. These include the four major NCD risk factors - tobacco use, harmful use of alcohol, unhealthy diet and physical inactivity - and to consider further targets relating to obesity, fat intake, alcohol, cholesterol and health system responses, such as availability of essential medicines for NCDs."

WHO is "on track" to developing such specific targets, asserts Dr. Timothy Armstrong, coordinator for surveillance and population-based prevention with WHO's Department of Chronic Diseases and Health Promotion. "The member states are very comfortable with the process to date."

Yet that will likely prove extremely tricky, given the thorny history of international food and trade negotiations and the demands from international nongovernmental organizations for transparency and accountability mechanisms to ensure that industry's role in reducing premature deaths from NCDs is properly defined.

WHO's approach is to give corporations a central role in forging global strategies to tackle NCDs. It's an approach which the NCD Alliance, which accepts substantial funding from pharmaceutical firms, favours.

But others are wary. "The huge risk is that the drivers of the NCDs are the very companies that the UN wants to partner with," says Patti Rundall, director of the London, England-based International Baby Food Action Network. The steadfast insistence by Canada and the United States that corporations be given significant steering power within the UN's NCD efforts is "happening in the face of growing concerns among developing nations," she adds.

Others warn that industry's role will become even more problematic once architects of the global plan turn their attention to issues like marketing.

Restrictions on television advertising must be a core element of the effort to reduce NCDs and "WHO must now come to grips with cross border marketing," says Indrani Thuraisingham, director of Asia Pacific and the Middle East for Consumers International. As an example, she cites a recent television advertising campaign in Malaysia in which mothers were exhorted by an American fast food chain to abandon shopping for fruit and vegetables and instead buy deep-fried chicken and soft drinks. "The fast food chains are expanding rapidly here and they do not offer any of the more nutritious products they now sell in rich countries."
Equally problematic are WHO's ongoing efforts to develop a surveillance framework for NCDs, says Stefano Campostrini, professor of social statistics at University of Ca' Foscari of Venice, Italy. He charges that WHO is relying on an outdated and limited surveillance methodology that fails to incorporate data on basic social determinants of health such as income and education.

Armstrong dismisses that charge. "We now have sufficient data to set the baselines for targets for action on the NCDs," he insists. "We have strong data from 140 countries."

Others say the financially troubled WHO lacks the financial resources to craft a global surveillance framework free from conflict of interest. "WHO was originally established to serve as a global organization with the core capacity for purposes such as tackling the NCDs," says Devi Sridhar, a lecturer in global health politics and codirector of the Centre for AIDS Interdisciplinary Research at the University of Oxford in England.

But UN member states have not funded WHO sufficiently to confront the issue, Sridhar says. "WHO's current funding model is not appropriate. There has been a severe erosion of its core purposes." - Paul Christopher Webster, Toronto, Ont.

CMAJ 2012. DOI:10.1503/cmaj.109-4224 